\title{
Right ventricular regional contraction patterns in normal subjects using cardiac magnetic resonance imaging - a five-year follow up study
}

\author{
Ali Salah*, Simcha Pollack, Nathaniel Reichek and Jie J Cao
}

Address: St Francis Hospital, Roslyn, NY, USA

* Corresponding author

from 13th Annual SCMR Scientific Sessions

Phoenix, AZ, USA. 21-24 January 2010

Published: 21 January 2010

Journal of Cardiovascular Magnetic Resonance 20 10, I2(Suppl I):O99 doi:I0.1 I86/I532-429X-I2-SI-O99

This abstract is available from: http://jcmr-online.com/content/I2/SI/O99

(c) 2010 Salah et al; licensee BioMed Central Ltd.

\section{Background}

Right ventricular (RV) regional wall motion assessment is important in evaluation of arrhythmogenic RV dysplasia. However, the prevalence and evolution of variations in RV regional contraction pattern in normal subjects is unclear

\section{Purpose}

We sought to compare the prevalence of variations in RV regional contraction patterns and their relationship to RV volume and mass index in normal subjects by cardiac MRI in a cross-sectional study with a 5-year follow up.

\section{Methods}

Subjects $(\mathrm{N}=81)$ were normotensive, non-diabetic, nonobese and without cardiovascular disease screened by history, echocardiography and ECG at baseline. Cardiac MRI was performed using SSFP cine imaging with prospective gating at baseline and retrospective gating at follow up. Variant RV regional contraction patterns were defined as systolic and diastolic focal outpouchings in 4 chamber, short axis, 3 chamber and RV outflow tract views. The length of segments showing focal outpouching and their relationship to the moderator band insertion were determined. We reported findings at 5 -year follow up and compared that with baseline findings using repeated measures ANOVA for continuous variables and McNemar's nonparametric test for dichotomous data.

\section{Results}

Mean age at intake was $54 \pm 13$ years and 44 (54\%) were females. Systolic focal outpouching occurred in 33/81 subjects (41\%) and 25/33 (75\%) occurred at end systole. All 12 instances (15\%) of diastolic focal outpouching were found in mid diastole and none at end diastole. Most systolic 20/33 (61\%) and diastolic $9 / 12$ (75\%) focal outpouchings were related to an insertion site of the moderator band. Mean length of outpouchings was $4.2 \pm 2.3$ $\mathrm{mm}$. Among all the views analyzed, the 4 chamber view had the highest frequency of outpouching 45/61(74\%). Comparing those with and without outpouching there was no difference in RV volume, ejection fraction (EF) or mass $(p=N S)$. Compared to intake there was no difference in the presence, location and dimensions of focal outpouchings at 5 -year follow up and no additional outpouchings were present at follow up. There was also no difference in the temporal change in RV volume, $\mathrm{EF}$ and mass between groups with and without RV focal outpouching.

\section{Conclusion}

$\mathrm{RV}$ focal outpouching is common in carefully screened normal subjects and is closely associated with moderator band insertions. However, end diastolic focal outpouchings are rare. The presence, location and length of outpouchings did not change over a 5 -year period and there were no cross-sectional or longitudinal differences in RV volume, EF and mass between groups with and without outpouching. 